\title{
Highly selective solid electrolyte sensor for the analysis of gaseous mixtures
}

\author{
Matthias Schelter $^{1}$, Jens Zosel ${ }^{1}$, Wolfram Oelßner ${ }^{1}$, Ulrich Guth ${ }^{1,2}$, and Michael Mertig ${ }^{1,2}$ \\ ${ }^{1}$ Kurt-Schwabe-Institut für Mess- und Sensortechnik e.V. Meinsberg, Kurt-Schwabe-Straße 4, \\ 04736 Waldheim, Germany \\ ${ }^{2}$ Technische Universität Dresden, Department of Physical Chemistry, 01062 Dresden, Germany
}

Correspondence to: Jens Zosel (zosel@ksi-meinsberg.de)

Received: 25 May 2016 - Revised: 4 August 2016 - Accepted: 9 August 2016 - Published: 1 September 2016

\begin{abstract}
The operation principle of a commercially available solid electrolyte sensor was modified with respect to applications in flowing gaseous mixtures containing $\mathrm{H}_{2}$ and $\mathrm{O}_{2}$. For this purpose the generally applied coulometric or potentiometric operation mode was replaced by cyclic voltammetry. By varying the sensor temperature, electrode area and potential scan rate, the conditions for the characteristic peak formation for every gas component were determined. While hydrogen oxidation peaks arise at potential scan rates up to $100 \mathrm{mV} \mathrm{s}^{-1}$, oxygen reduction peaks develop between 200 and $1000 \mathrm{mV} \mathrm{s}^{-1}$. A linear relationship between peak area/peak height and concentration was found at concentrations $\phi\left(\mathrm{H}_{2}\right)<100$ vol. ppm and $\phi\left(\mathrm{O}_{2}\right) \leq 500$ vol. ppm. It could be demonstrated that hydrogen can be measured selectively at catalytically highly active Pt electrodes even in gas mixtures with comparably high oxygen concentrations by using cyclic voltammetry.
\end{abstract}

\section{Introduction}

The control of mobile and stationary combustion processes and also medical, environmental, safety, industrial and biotechnological applications often require the simultaneous measurement of redox active gaseous components like hydrogen and oxygen in non-equilibrated mixtures. If stationary methods like potentiometry, amperometry or coulometry are applied to conventional solid electrolyte sensors (SESs) based on yttria-stabilized zirconia (YSZ), these are not suited for this purpose. Due to the fact that the mixture is rapidly equilibrated at the hot and catalytically highly active Pt electrodes, an SES cell of the type "gas mixture, Pt|YSZ|Pt,air" generates a voltage corresponding to the equilibrium partial pressure of oxygen in the measured gas mixture. Therefore, each component reacting with oxygen at the hot Pt surface contributes to the measured voltage, which makes the qualitative and quantitative determination of these species impossible.

Contrary to these stationary methods, dynamic measurements like impedance spectroscopy can enable concentration measurements of single components in non-equilibrated gas mixtures (Schindler et al., 1989). The investigations presented here are directed to the ability of cyclic voltammetry (CV) (Henze, 2001) to enhance the selectivity of solid electrolyte sensors. The linear temporal variation of the polarization voltage $U_{\mathrm{p}}(t)$ between two reversal points enables the separated selective determination of liquid analytes if they differ in diffusion, charge transfer or reaction potential. It will be demonstrated that this method also enables the selective measurement of combustible gases like hydrogen in oxygen-containing mixtures at hot and catalytically highly active gas electrodes.

\section{Experimental}

The SES shown in Fig. $1\left(\mathrm{O}_{2}\right.$-DF-28.0 from ZIROX Sensoren \& Elektronik GmbH, Greifswald, Germany) contains two alternatively used and separately heatable $\left(650-800^{\circ} \mathrm{C}\right)$ cells of the type "measuring gas,Pt|YSZ|Pt,air" on a YSZ tube $\left(\mathrm{ZrO}_{2}\right.$ stabilized with $\left.8 \mathrm{~mol} \% \quad \mathrm{Y}_{2} \mathrm{O}_{3}\right)$. The electrode sizes (inside/outside) are as follows: cell $1: 7.5 / 11.3 \mathrm{~cm}^{2}$; cell 2: $0.75 / 1.13 \mathrm{~cm}^{2}$. As indicated in Fig. 1 , the electrodes of both cells ref1 and ref2, situated on the outer surface of the 


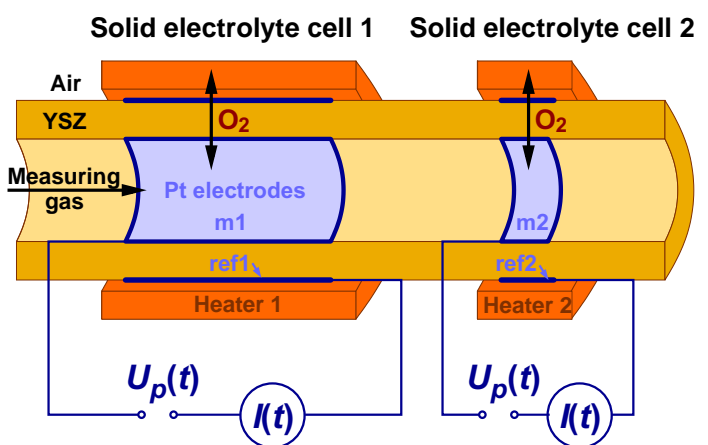

Figure 1. Experimental setup of the solid electrolyte sensor (electrode areas A: cell 1: $\mathrm{A}(\mathrm{m} 1)=7.5 \mathrm{~cm}^{2}$ and $\mathrm{A}(\operatorname{ref} 1)=11.3 \mathrm{~cm}^{2}$; cell 2: $\mathrm{A}(\mathrm{m} 2)=0.75 \mathrm{~cm}^{2}$ and $\left.\mathrm{A}(\operatorname{ref} 2)=1.13 \mathrm{~cm}^{2}\right)$ with a cyclic voltammetric measuring unit; $U_{\mathrm{p}}(t)$ : linearly and cyclically varying polarization voltage; $I(t)$ : measured current.

YSZ tube (YSZ|Pt,air), serve as reference as well as counter electrodes. Open-circuit potential (OCP) and cyclic voltammograms (in the following referred to as voltammograms) were taken by the electrochemical multipurpose measurement system Reference $600^{\mathrm{TM}}$ (Gamry Instruments, Warminster, USA). During the first cycle of the cyclic voltammetric experiments conditioning processes occur. For this reason in each experiment the second cycle was evaluated to get reproducible results.

Measuring gases with predefined compositions were mixed from nitrogen, synthetic air and a test gas of 1001 vol. ppm $\mathrm{H}_{2}$ in $\mathrm{N}_{2}$, all with quality 5.0, by mass flow controllers from Brooks Instruments (Hatfield, USA). The measuring gas passes the YSZ tube at flow rates between 5 and $50 \mathrm{sccm}$ (standard cubic centimetres per minute) (Schelter et al., 2012).

\section{Results}

\subsection{Characteristic CV curves of the SES}

A closer look on the basic reaction mechanisms at a nitrogenrinsed electrode of a cell " $\mathrm{N}_{2}, \mathrm{Pt}|\mathrm{YSZ}| \mathrm{Pt}$,air" during the scan of polarization voltage given in Fig. 2 reveals that at positive polarization voltages oxygen ions $\mathrm{O}^{2-}$ are pumped through YSZ into the nitrogen gas flow by reducing $\mathrm{O}_{2}$ from air at the outer reference/counter electrode and re-oxidizing them to $\mathrm{O}_{2}$ at the inner working electrode. Only the overall cell resistance controls the current in this range, which increases linearly with the polarization voltage. At negative polarization, the current tends to zero since $\mathrm{N}_{2}$ contains nearly no oxygen, which could be reduced at the working electrode (blocking electrode).

Polarizing backward in anodic direction and crossing OCP causes an exponential current increase, which can be described by the Butler-Volmer equation. Above $U_{\mathrm{p}}=0 \mathrm{~V}$ between both electrodes the ohmic range with linear current

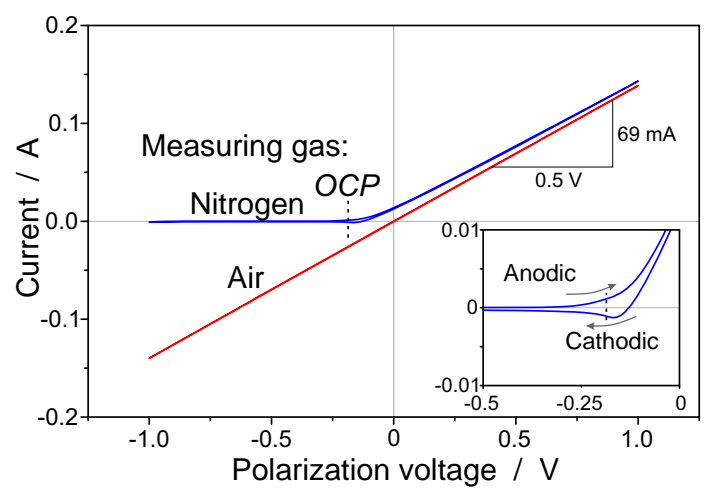

Figure 2. Characteristic curves of the solid electrolyte cell 1; cell temperature: $750{ }^{\circ} \mathrm{C}$; potential scan rate: $100 \mathrm{mV} \mathrm{s}^{-1}$; gas flow rate: $10 \mathrm{sccm}$; electrode size: $7.5 \mathrm{~cm}^{2}$; open-circuit potential of the cell with $\mathrm{N}_{2}$ as measuring gas: $-183.5 \mathrm{mV}$ (dashed lines). Inset: magnification of the curve with $\mathrm{N}_{2}$ as measuring gas in the range of -0.5 to $0 \mathrm{~V}$.

increase described above is reached again. The inset in Fig. 2 demonstrates clearly that the voltage scan in cathodic direction causes a current peak before OCP is crossed. This peak is caused mainly by residual oxygen, pumped into the cell in the anodic range before and leaving the cell with the gas flow. Furthermore, Fig. 2 contains the voltammogram (red line) of a gas-symmetrical SES with air at both electrodes. Due to the high diffusion rate of oxygen in the hot air, no mass transfer limitation occurs at the electrodes, and the current is controlled solely by the cell resistance as discussed before. Gas symmetry causes symmetry of the current curve with respect to the zero point, which in this case is also the open-circuit voltage if thermally induced asymmetry potentials are neglected.

The overall cell resistance $R_{\mathrm{O}}$, calculated from the slope of the current-voltage curve in Fig. 2 , amounts to $R_{\mathrm{O}}=7.2 \Omega$ and represents the sum of polarization resistances of both electrodes $R_{\mathrm{pol} 1 / 2}$ and the electrolyte resistance $R_{\mathrm{el}}$. The latter parameter can be calculated to $R_{\mathrm{el}}=0.55 \Omega$ from the YSZ ionic conductivity (according to Park and Blumenthal (1989): $2.07 \mathrm{~S} \mathrm{~m}^{-1}$ at $750^{\circ} \mathrm{C}$ ), the electrode area $A_{\mathrm{el}}=$ $8.72 \mathrm{~cm}^{2}$ and the electrolyte thickness $d_{\mathrm{el}}=1.0 \mathrm{~mm}$. Therefore, the mean electrode-area-related polarization resistance can be estimated as $R_{\mathrm{pol}, \mathrm{m}} \times A_{\mathrm{el}} \approx 30 \Omega \times \mathrm{cm}^{2}$. Due to the curved geometry of the solid electrolyte, the areas of the outer electrodes are about $50 \%$ greater than those of the inner ones. The area $A_{\mathrm{el}}=8.72 \mathrm{~cm}^{2}$ of cell 1 was calculated as the logarithmic mean value of the two electrode areas. Since the distance between the two electrodes is comparatively low, the electrical stray fields within the electrolyte can be neglected.

The following investigations at the SES with two separated gas spaces given in Fig. 1 were carried out mainly within the range of cathodic polarization of the measuring electrode, where the oxidation and reduction processes of the analytes hydrogen and oxygen dominate. 


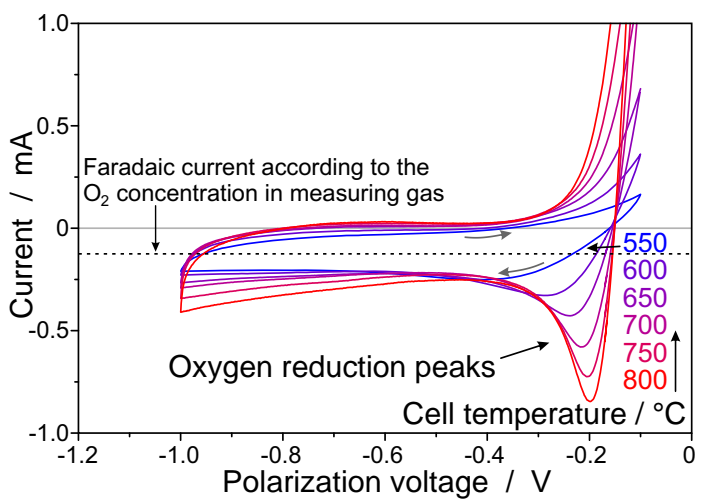

Figure 3. Voltammograms about the variation of the cell temperature; measuring gas: 40 vol. ppm $\mathrm{O}_{2}$ in $\mathrm{N}_{2}$; gas flow rate: $10 \mathrm{sccm}$; electrode size: $0.75 \mathrm{~cm}^{2}$; open-circuit potential: $-150 \mathrm{mV}\left(550{ }^{\circ} \mathrm{C}\right)$ to $-200 \mathrm{mV}\left(800^{\circ} \mathrm{C}\right)$; potential scan rate: $1 \mathrm{~V} \mathrm{~s}^{-1}$; start potential: $-0.17 \mathrm{~V}$; the second cycle is shown.

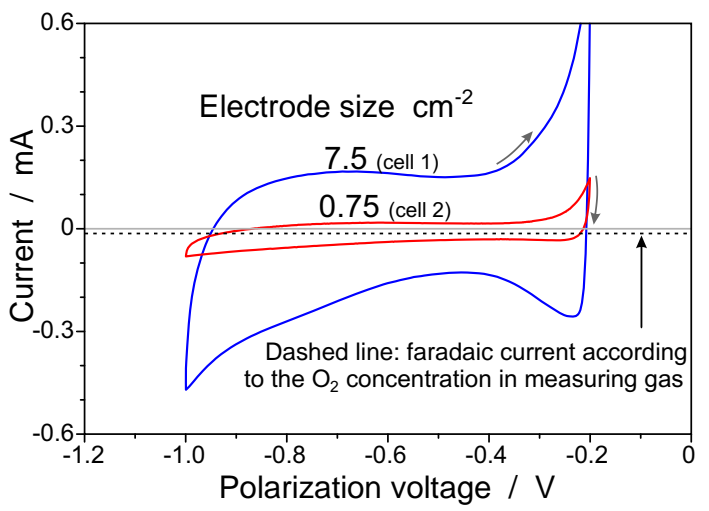

Figure 4. Voltammograms about the variation of the electrode size; measuring gas: 5 vol. ppm $\mathrm{O}_{2}$ in $\mathrm{N}_{2}$; gas flow rate: $10 \mathrm{sccm}$; cell temperature: $750{ }^{\circ} \mathrm{C}$; open-circuit potential: $-235 \mathrm{mV}$; potential scan rate: $200 \mathrm{mV} \mathrm{s}^{-1}$; start potential: $-0.20 \mathrm{~V}$; the second cycle is shown.

\subsection{Peak formation in hydrogen- and oxygen-containing gases}

To find experimental conditions which facilitate the peak formation typical for $\mathrm{CV}$ even in nitrogen-based measuring gases with traces of $\mathrm{H}_{2}, \mathrm{O}_{2}$ and/or $\mathrm{H}_{2} \mathrm{O}$, influencing parameters such as sensor temperature, electrode area and potential scan rate were varied. The results of these investigations are discussed below.

The voltammograms taken from $\mathrm{O}_{2}$-containing mixtures at different sensor temperatures given in Fig. 3 illustrate that the reduction peak increases with temperature. Additionally, the peak minimum is shifted in anodic direction at increasing temperature. Above $600^{\circ} \mathrm{C}$, the area of this arising oxygen reduction peak becomes accessible for quantitative analysis.

The voltammograms for two different electrode areas illustrated in Fig. 4 show a large increase of the current hys-

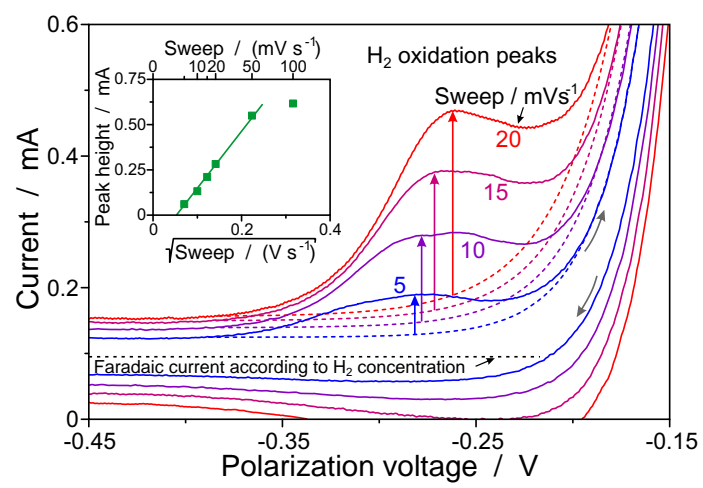

Figure 5. Voltammograms at variable potential scan rates; the baselines (represented by dashed + coloured lines) are the exponentially increasing currents resulting from the increasing oxygen pump currents at increasing polarization voltages; the lengths of the arrows represent the heights of the $\mathrm{H}_{2}$ oxidation peaks. Inset: peak heights of the $\mathrm{H}_{2}$ oxidation peaks in relation to the square root of the potential scan rate; electrode size: $7.5 \mathrm{~cm}^{2}$; cell temperature: $800^{\circ} \mathrm{C}$; measuring gas: 100 vol. ppm $\mathrm{H}_{2}+17$ vol. ppm $\mathrm{O}_{2}$ in $\mathrm{N}_{2}$; gas flow rate: $10 \mathrm{sccm}$; open-circuit potential: $-971.1 \mathrm{mV}$; the second cycle is shown.

teresis between cathodic and anodic scan directions with increasing electrode area. This hysteresis is caused mainly by the charge reversal within the double-layer capacity. Because these capacitive currents diminish the signal-to-noise ratio of voltammetric measurements, the electrode area should be kept as small as possible for CV.

Classical voltammetry at liquid electrolyte cells is characterized by peak heights increasing linearly with the square root of the potential scan rate $\mathrm{d} U_{\mathrm{p}} / \mathrm{d} t$ as described by the Randles-Sevčik equation. To prove if this dependency appears in the same manner at SES, voltammograms were taken with different potential scan rates at an SES of the type " $\mathrm{H}_{2}$, $\mathrm{H}_{2} \mathrm{O}, \mathrm{N}_{2}, \mathrm{Pt}|\mathrm{YSZ}| \mathrm{Pt}$,air". Although the hydrogen is oxidized according to Faraday's law within the complete scanned potential range, hydrogen-related oxidation peaks appear between -0.35 and $-0.20 \mathrm{~V}$ vs. Pt/air reference, as the results shown in Fig. 5 indicate. These peaks have the shape of a shoulder within the exponentially increasing oxygen pump current, indicated in Fig. 5 by dashed lines. The peak heights were calculated by subtracting the oxygen pump current from the measured current.

As shown in the inset of Fig. 5, the peak height increases linearly with the square root of the potential scan rate up to $\mathrm{d} U_{\mathrm{p}} / \mathrm{d} t=50 \mathrm{mV} \mathrm{s}^{-1}$. As can be seen in Fig. 6, at higher scan rates the $\mathrm{H}_{2}$ oxidation peaks are more and more hidden behind the exponential oxygen pump current increase, resulting in a sharp bend of the peak height curve in the inset of Fig. 5. It can be concluded that the classical voltammetric relationships known from liquid electrolyte experiments are also valid for SES, even if they are equipped with relatively large electrodes. 


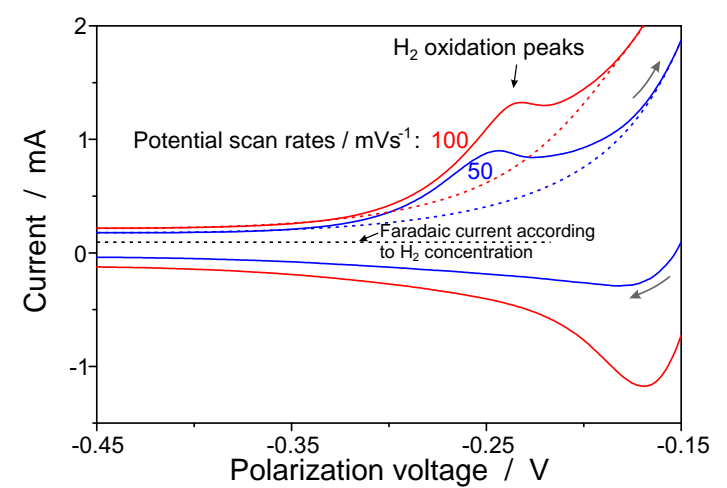

Figure 6. Voltammograms at higher potential scan rates than shown in Fig. 5.

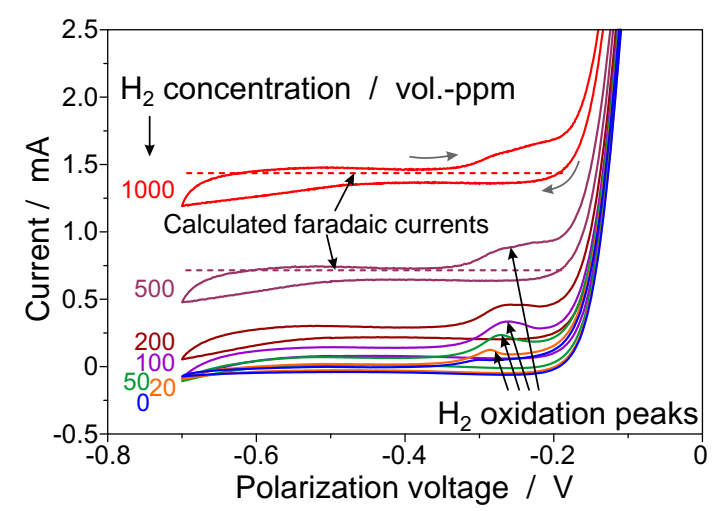

Figure 7. Voltammograms for measuring gases at different $\mathrm{H}_{2}$ concentrations; cell temperature: $750{ }^{\circ} \mathrm{C}$; gas flow rate: $10 \mathrm{sccm}$; electrode size: $7.5 \mathrm{~cm}^{2}$; potential scan rate: $10 \mathrm{mV} \mathrm{s}^{-1}$; the second cycle is shown.

\subsection{SES sensitivity to $\mathrm{H}_{2}$ and $\mathrm{O}_{2}$}

The sensitivity of the voltammetrically operated SES was studied at the optimized sensor parameters discussed above. Results of measurements with gases of different $\mathrm{H}_{2}$ concentrations are illustrated in Fig. 7. The peak heights and areas were calculated as described above by subtracting the exponentially increasing oxygen pump current from the measured current. The resulting values given in Fig. 8 indicate that both parameters increase nearly linearly with $\mathrm{H}_{2}$ concentration till $\phi\left(\mathrm{H}_{2}\right)=50$ vol. ppm. Above $\phi\left(\mathrm{H}_{2}\right)=100$ vol. ppm the peak parameters decrease with ascending concentration since the peak is hidden more and more behind the exponential current rise.

The voltammograms also document that the curves are shifted parallel to higher anodic currents with rising $\mathrm{H}_{2}$ concentration. The polarization-dependent dynamic peak current is superimposed by the faradaic current resulting from hydrogen oxidation, which in this voltage range is independent from the polarization. The dashed lines in Fig. 7 representing these calculated faradaic currents are positioned between

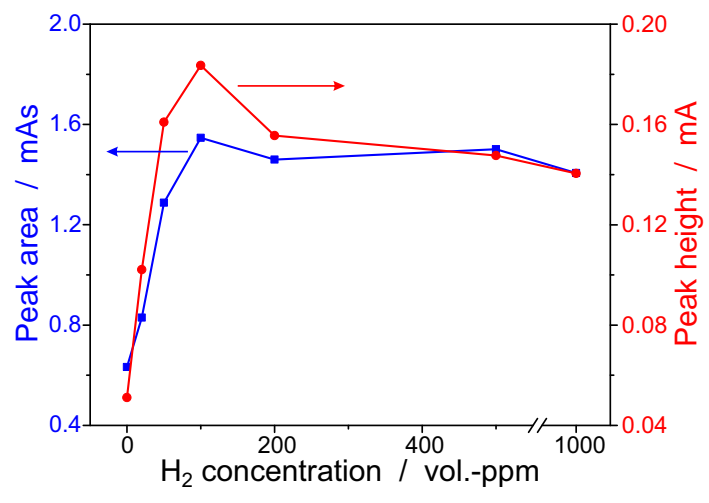

Figure 8. Heights and areas of the $\mathrm{H}_{2}$ peaks from Fig. 7 depending on the $\mathrm{H}_{2}$ concentration.

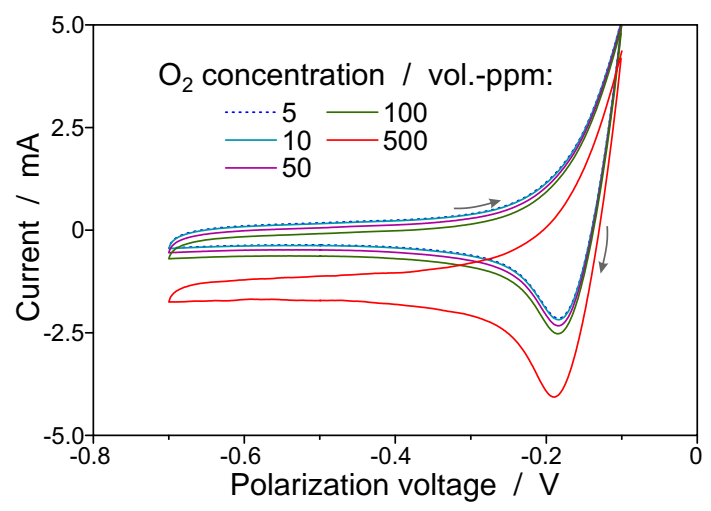

Figure 9. Voltammograms for measuring gases at different $\mathrm{O}_{2}$ concentrations; potential scan rate: $200 \mathrm{mV} \mathrm{s}^{-1}$; electrode size: $7.5 \mathrm{~cm}^{2}$; open-circuit potential: $-241 \mathrm{mV}\left(5 \mathrm{vol} . \mathrm{ppm} \mathrm{O}_{2}\right)$ to $-135 \mathrm{mV}\left(500 \mathrm{vol} . \mathrm{ppm} \mathrm{O}_{2}\right)$; gas flow rate: $10 \mathrm{sccm}$; cell temperature: $750{ }^{\circ} \mathrm{C}$; the second cycle is shown.

the measured currents in cathodic and anodic direction in the polarization range $U_{\mathrm{p}}=-0.6$ to $-0.2 \mathrm{~V}$. This faradaic conversion of $\mathrm{H}_{2}$ in the continuously flowing measuring gas is caused by the relatively large area of the electrode and its high catalytic activity.

As expected and shown in Fig. 9, the variation of oxygen concentration also induces a shift of the voltammograms along the current axis, albeit in the opposite direction compared to hydrogen-containing gases. Calculated peak heights in Fig. 10 exhibit a linear increase in the complete investigated concentration range. Because oxygen is pumped into the measuring gas flow within each cycle at polarization voltages above $-0.15 \mathrm{~V}$ (see also Sect. 3.2), the regression line does not meet the point of origin. The results prove that small oxygen concentrations can be measured precisely despite the much higher oxygen quantities pumped into the measuring gas during each cycle. 


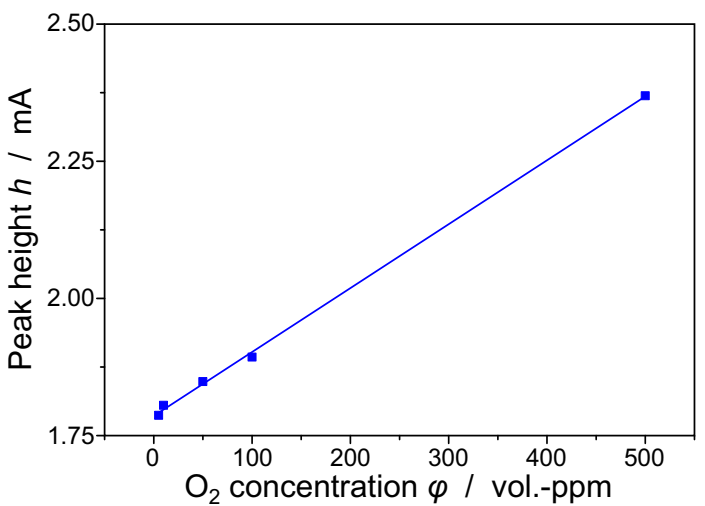

Figure 10. Heights of the $\mathrm{O}_{2}$ peaks from Fig. 9 depending on the $\mathrm{O}_{2}$ concentration; the peak heights were calculated as the difference between the current at the peak minimum and the current at $-0.55 \mathrm{~V}$. Linear fit function: $h / \mathrm{mA}=1.16 \times$ $10^{-3} \varphi$ vol. $\mathrm{ppm}^{-1}+1.786$.

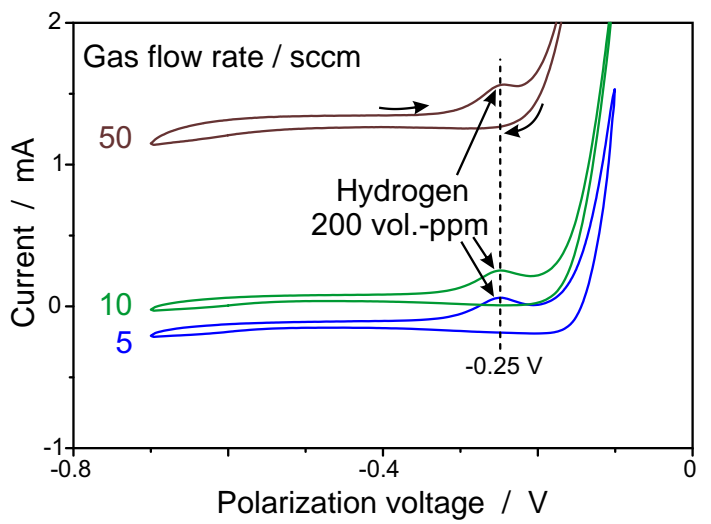

Figure 11. Voltammograms for measuring gases with 200 vol. ppm $\mathrm{H}_{2}$ - each at different gas flow rates; cell temperature: $700^{\circ} \mathrm{C}$; potential scan rate: $10 \mathrm{mV} \mathrm{s}^{-1}$; electrode size: $7.5 \mathrm{~cm}^{2}$; open-circuit potential: $-161 \mathrm{mV}(5 \mathrm{sccm})$ to $-1030 \mathrm{mV}(50 \mathrm{sccm})$; the second cycle is shown.

\subsection{Cross sensitivities}

The voltammograms in Fig. 11 taken from gas mixtures with 200 vol. ppm $\mathrm{H}_{2}$ in $\mathrm{N}_{2}$ at different flow rates between 5 and $50 \mathrm{sccm}$ prove that neither the height nor the potential of the hydrogen peak are influenced by the flow rate. These parameters are additionally specified in Table 1 . A small leakage of oxygen into the measuring gas flow during the measurements given in Fig. 11 caused different oxygen concentrations and reducing currents. The resulting oxygen concentrations calculated from OCP taken before each voltammogram and from the mean values of currents at cathodic and anodic polarization direction at $U_{\mathrm{p}}=-450 \mathrm{mV}$ are specified in Table 2 . Despite the intensively changing oxygen concentration, the hydrogen-related oxygen peak changes neither its height nor its potential located at $U_{\mathrm{p}}=-0.25 \mathrm{~V}$. This proves that cross sensitivities between oxidizable and reducible gas
Table 1. Peak data of the $\mathrm{H}_{2}$ oxidation peaks from Fig. 11 .

\begin{tabular}{lrr}
\hline $\begin{array}{l}\text { Gas flow } \\
(\mathrm{sccm})\end{array}$ & $\begin{array}{r}\text { Centre of } \\
\text { peak }(\mathrm{V})\end{array}$ & $\begin{array}{r}\text { Peak height } \\
(\mathrm{mA})\end{array}$ \\
\hline 5 & -0.250 & 0.149 \\
10 & -0.250 & 0.153 \\
50 & -0.250 & 0.146 \\
\hline
\end{tabular}

Table 2. Oxygen concentrations in measuring gases during the voltammetric measurements shown in Fig. 11.

\begin{tabular}{lrr}
\hline $\begin{array}{l}\text { Gas flow } \\
(\mathrm{sccm})\end{array}$ & $\begin{array}{r}\text { OCP } \\
(\mathrm{mV})\end{array}$ & $\begin{array}{r}\mathrm{O}_{2} \text { conc. } \\
(\text { vol. ppm })\end{array}$ \\
\hline 5 & -161 & 195 \\
10 & -770 & 100 \\
50 & -1030 & 20 \\
\hline
\end{tabular}

components can be circumvented completely for SESs operated by $\mathrm{CV}$ with analyte adjusted scan rate.

\section{Conclusions}

A commercially available solid electrolyte sensor based on yttria-stabilized zirconia was operated by means of cyclic voltammetry in a flow-through modus. Varying the sensor parameters temperature, electrode area, potential scan rate and gas flow rate, conditions were found which enable the formation of characteristic peaks in gas mixtures containing traces of hydrogen and oxygen.

The height and area of the measured peaks increase linearly with concentration in the case of hydrogen at concentrations $<100 \mathrm{vol}$. ppm and in case of oxygen in the complete investigated range till $500 \mathrm{vol}$. ppm.

While hydrogen oxidation peaks occur at scan rates $\leq 100 \mathrm{mV} \mathrm{s}^{-1}$, oxygen reduction peaks were found at scan rates between 200 and $1000 \mathrm{mV} \mathrm{s}^{-1}$. The gas flow rate does not influence the peak parameters in the investigated range.

It could be demonstrated clearly that, by means of an otherwise non-selective solid electrolyte sensor operated with cyclic voltammetry, traces of hydrogen and oxygen can be measured simultaneously with full selectivity.

Acknowledgements. The investigations were carried out partially within the projects VESBA (support code 03KB045A) and LIMOS (support code 22011110) funded by the German Ministry of Environment, Nature Conservation, Building and Nuclear Safety (BMU) and Ministry of Food and Agriculture (BMEL) respectively. The authors are responsible for the content of this paper and are thankful for the funding.

Edited by: M. Kusnezoff

Reviewed by: two anonymous referees 


\section{References}

Henze, G.: Polarographie und Voltammetrie: Grundlagen und analytische Praxis, Chapter: Methoden, Springer, Berlin, 22-65, 2001.

Park, J.-H. and Blumenthal, R. N.: Electronic Transport in 8 Mole Percent $\mathrm{Y}_{2} \mathrm{O}_{3}-\mathrm{ZrO}_{2}$, J. Electrochem. Soc., 136, 2867-2876, doi:10.1149/1.2096302, 1989.
Schelter, M., Zosel, J., Oelßner, W., Guth, U., and Mertig, M.: A solid electrolyte sensor for trace gas analysis, Sensor Actuat. BChem., 187, 209-214 doi:10.1016/j.snb.2012.10.111, 2012.

Schindler, K., Schmeisser, D., Vohrer, U., Wiemhöfer, H. D., and Göpel, W.: Spectroscopic and electrical studies of yttriastabilized zirconia for oxygen sensors, Sensor Actuator., 17, 555-568, doi:10.1016/0250-6874(89)80045-9, 1989 